\title{
Treatment of American tegumentary leishmaniasis in special populations: a summary of evidence
}

\author{
Juliana Saboia Fontenele e Silva ${ }^{[1]}$, Tais Freire Galvao ${ }^{[2]}$, Maurício Gomes Pereira ${ }^{[2]}$ \\ and Marcus Tolentino Silva ${ }^{[3]}$
}

[1]. Laboratório de Dermatomicologia, Faculdade de Medicina, Universidade de Brasília, Brasília, DF. [2]. Faculdade de Medicina, Universidade de Brasília, Brasília, DF. [3]. Departamento de Ciência e Tecnologia, Ministério da Saúde, Brasília, DF.

\begin{abstract}
We aimed to assess and synthesize the information available in the literature regarding the treatment of American tegumentary leishmaniasis in special populations. We searched MEDLINE (via PubMed), EMBASE, LILACS, SciELO, Scopus, Cochrane Library and mRCT databases to identify clinical trials and observational studies that assessed the pharmacological treatment of the following groups of patients: pregnant women, nursing mothers, children, the elderly, individuals with chronic diseases and individuals with suppressed immune systems. The quality of evidence was assessed using the Grading of Recommendations, Assessment, Development and Evaluations (GRADE) approach. The available evidence suggests that the treatments of choice for each population or disease entity are as follows: nursing mothers and children (meglumine antimoniate or pentamidine), patients with renal disease (amphotericin B or miltefosine), patients with heart disease (amphotericin B, miltefosine or pentamidine), immunosuppressed patients (liposomal amphotericin), the elderly (meglumine antimoniate), pregnant women (amphotericin B) and patients with liver disease (no evidence available). The quality of evidence is low or very low for all groups. Accurate controlled studies are required to fill in the gaps in evidence for treatment in special populations. Post-marketing surveillance programs could also collect relevant information to guide treatment decision-making.
\end{abstract}

Keywords: American tegumentary leishmaniasis. Special populations. Treatment. Evidence.

\section{INTRODUCTION}

Some patient populations present challenges for the treatment of American tegumentary leishmaniasis (ATL). These populations include pregnant women, nursing mothers, children, the elderly, individuals with chronic diseases and individuals with suppressed immune systems. These individuals are excluded from clinical trials ${ }^{1}$ to achieve homogeneous groups. As a result, the available evidence on the effectiveness and safety of treatments in special populations of patients is scarce ${ }^{2}$, which makes clinical decision-making difficult.

The therapeutic options available to treat ATL are limited, and the current evidence for recommendations on the treatment of cutaneous leishmaniasis (CL) is generally weak ${ }^{3-5}$. Pentavalent antimonials ( $\mathrm{SbV}$ ) have been the drugs of choice for more than six decades. However, they have high toxicity and are contraindicated in children, pregnant and breastfeeding women and chronically ill patients ${ }^{6-9}$. Pentamidine isethionate and amphotericin B are the second-line treatments ${ }^{7,9,10}$. In the last decade, miltefosine was introduced as an oral alternative ${ }^{11}$

Address to: Dra Juliana Saboia Fontenele e Silva. Lab. de Dermatomicologia/ FM/UnB. Campus Universitário, Sala BC 104, Asa Norte, 70910-900 Brasília, DF, Brasil.

Phone: 5561 8133-8370; Fax: 5561 3364-2772

e-mail: jusaboia@hotmail.com

Received 15 May 2013

Accepted 31 July 2013 whose effectiveness for treating CL and mucosal leishmaniasis (ML) was shown in clinical trials conducted in Guatemala, Colombia, Bolivia and Brazil ${ }^{12-17}$.

The present study reports results found from a literature review of the treatment of ATL in special populations.

\section{METHODS}

Study type: this is a summary of evidence with systematic search, selection and data extraction processes.

Study eligibility criteria: clinical trials and observational studies were considered eligible if they assessed pharmacological treatment using the main drugs used in the treatment of ATL (meglumine antimoniate, amphotericin, pentamidine isethionate and miltefosine) in one of the following patient populations: pregnant women, nursing mothers, children (individuals under 16 years of age), the elderly (individuals over 60 years or age) and individuals with renal disease, heart disease, liver disease or suppressed immune systems (e.g., individuals with human immunodeficiency virus (HIV) infection or individuals receiving therapy with immunosuppressive drugs or bone marrow or solid organ transplantation). For renal, heart and liver disease, we considered the same definition that the included papers employed.

Studies regarding the treatment of diseases other than ATL, such as mycoses, were not considered eligible. However, when there was a lack of specific studies for ATL in special groups, additional studies regarding visceral leishmaniasis (VL) or Old World CL were also assessed. 


\section{LITERATURE SEARCH}

In November 2010, a broad search was conducted by one of the authors (JSFS) in MEDLINE (via PubMed), EMBASE, LILACS, SciELO, Scopus, Cochrane Library and mRCT. There was no restriction on language or publication date. The search strategy included the following terms: leishmaniasis, cutaneous, mucocutaneous, pentamidine, amphotericin B, meglumine antimoniate, miltefosine, adverse effects, new world leishmaniasis, American leishmaniasis, side effects and undesirable effects. The last search update was performed on July 2013.

Secondary sources of information were also consulted: the Centers for Disease Control and Prevention (CDC), the Food and Drug Administration (FDA) and the World Health Organization (WHO) ${ }^{18-20}$.

Study selection and data extraction: one author selected the studies from the titles and abstracts (JSFS) and another confirmed the data (TFG). The same process was used to extract relevant information regarding anti-leishmanial drugs used in special populations.

Data analysis and critical appraisal: the studies were labeled as laboratory studies, case reports, case series, case-control studies, cohort studies, narrative reviews, systematic reviews or clinical trials and grouped according to the special population of patients studied: pregnant women, nursing mothers, children, the elderly, patients with chronic diseases and patients with suppressed immune systems.

Regarding the drugs used for treatment, the U.S. FDA Pregnancy Category Definitions ${ }^{18}$ were used to rate the best pharmacotherapy option for pregnant women. To classify the risk for nursing mothers, we adopted the WHO Breastfeeding and Maternal Medication Recommendations for Drugs ${ }^{20}$, which consider five categories ranging from compatible with breastfeeding to avoid using.

After the eligible studies were selected, the evidence presented was rated based on the Grading of Recommendations, Assessment, Development and Evaluations (GRADE) approach $^{21}$. No information produced by regulatory agencies was considered for the assessment of the quality of evidence.

\section{RESULTS AND DISCUSSION}

Ninety-seven references were found regarding therapeutic options for ATL treatment in pregnant women, nursing mothers, children, the elderly, and patients with renal disease, heart disease, liver disease or suppressed immune systems (Figure 1). Most of the included studies were case reports (Table 1). The special group with the highest number of publications was patients with suppressed immune systems. No description was found for anti-leishmaniasis therapy in nursing mothers. For children, six clinical trials were available. Although a clinical trial was found for the renal disease group, it was not considered for the treatment quality assessment because its purpose was the prevention of nephrotoxicity. The quality of the evidence was very low for most groups, including children (Table 2).

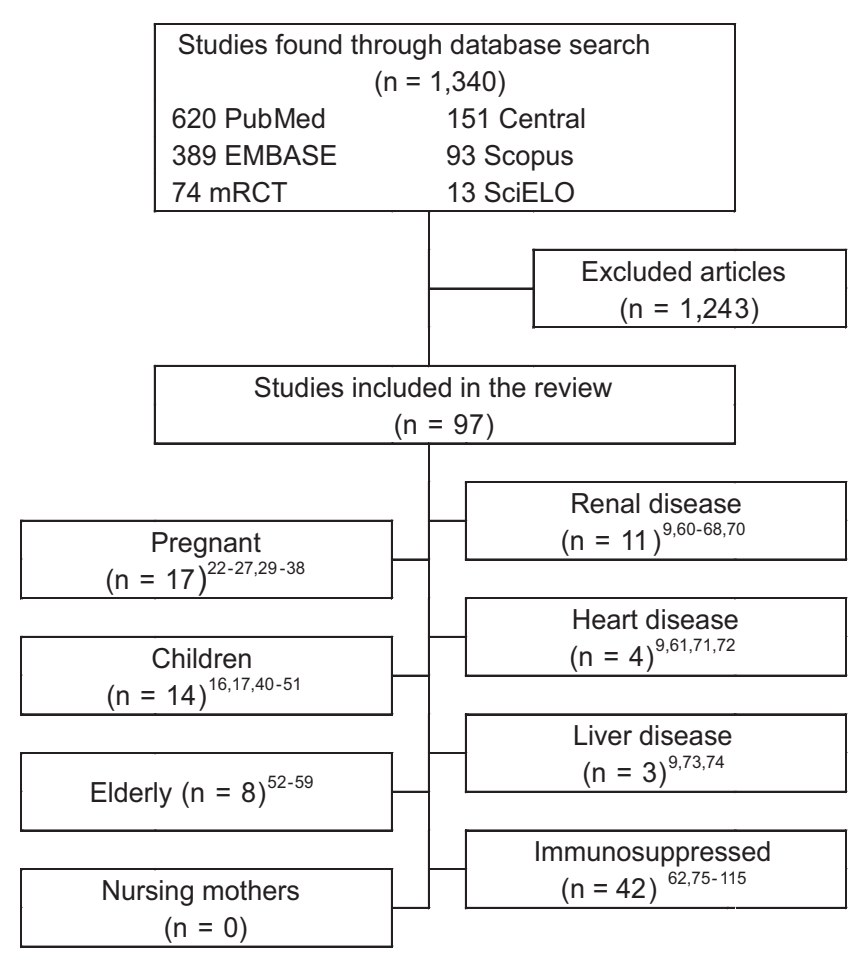

FIGURE 1 - Search results and selection of articles per special group. Note: The search on LILACS did not retrieve any results. References ${ }^{61}$ and ${ }^{62}$ were included for more than one group, what makes the total of included studies less than the sum of all studies by group. Numbers in superscript represent the references list.

Pregnant women: only amphotericin B is acceptable for use during pregnancy according to the $\mathrm{FDA}^{18}$ (Table 3). Although the FDA pregnancy category provides guidance regarding a drug's potential fetal risks, limitations such as a lack of a specific toxic dose or predisposing pregnancy trimester complicate its application ${ }^{22}$. Amphotericin B can cross the placenta and reach low concentrations in the amniotic fluid ${ }^{23}$, but its safety in pregnant women was established in the treatment of systemic mycoses ${ }^{18}$. No studies were found assessing the effectiveness of amphotericin B in ATL treatment. In pregnant women with VL, amphotericin is preferred over other drugs ${ }^{24}$. Moreover, there were no adverse effects on the fetus or abortions when it was used for VL during the first or second trimester ${ }^{25,26}$.

Information regarding meglumine antimoniate safety in pregnancy is scarce ${ }^{27}$. Pentavalent antimonials are considered a category $\mathrm{C}$ drug by the $\mathrm{FDA}^{18}$ (Table 3). Experimental studies in pregnant rats showed an increase in fetal skeletal malformations, particularly in the atlas bone ${ }^{28}$. In addition, this drug may be toxic to the embryo even in the absence of signs of maternal toxicity ${ }^{29}$.

In humans, the evidence for meglumine antimonite treatment in pregnant women with ATL is limited. There are two case reports of patients using the drug in the first trimester. The drug was discontinued as soon as pregnancy was identified without harm to fetus, pregnant mother or labor ${ }^{30}$. Other studies report the treatment of $70 \mathrm{VL}$ pregnant women with SbV. Among 
TABLE 1 - Studies classified according to type by each special group reported in this review.

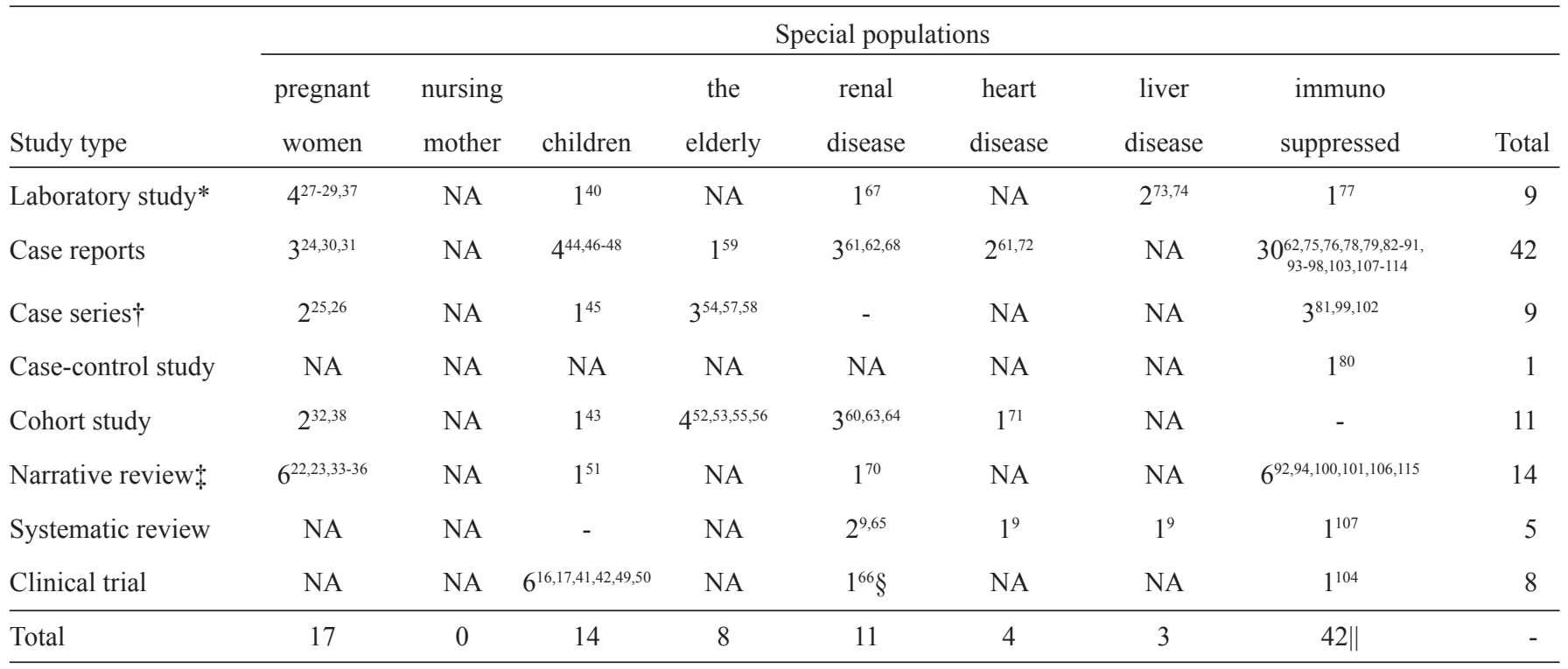

*Laboratory experimental studies; †includes retrospective studies of series of patients treated (medical records); $₫$ narrative review on the main therapeutic options available; $\S$ clinical trial on preventing amphotericin nephrotoxicity; $\|$ one study ${ }^{107}$ presented a case report and a systematic review in the same manuscript; NA: not available. Numbers in superscript represent the references list.

TABLE 2 - Quality of evidence for American tegumentary leishmaniasis therapy in special groups (Adapted from GRADE).

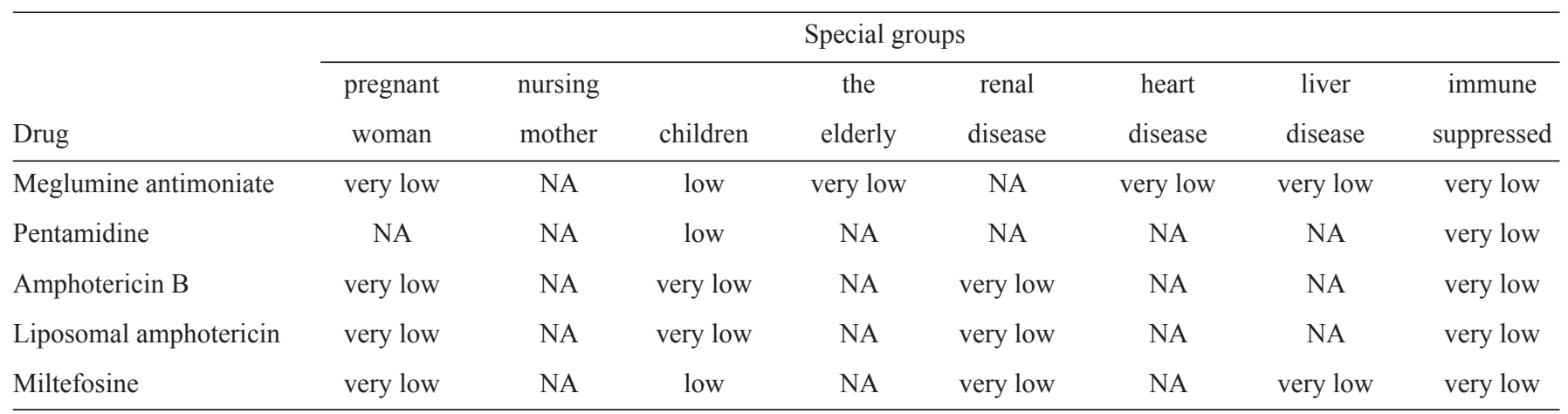

NA: not available; GRADE: Grading of Recommendations, Assessment, Development and Evaluations.

these 70 women, there were 16 cases of abortion in the first or second trimester ${ }^{26,31,32}$.

Pentamidine isethionate should be avoided during pregnancy. The FDA category risk for this drug is $\mathrm{C}$ (Table 3) because the drug's manufacturer did not conduct animal reproductive studies. In studies conducted after the drug was marketed, pentamidine was teratogenic but not embryocidal when administered to animals. Pentamidine may cross the human placenta $^{18}$.

Miltefosine has exhibited teratogenicity and should therefore not be administered to pregnant women ${ }^{33-35}$. Studies in rats and rabbits have demonstrated embryotoxicity, fetotoxicity and teratogenicity ${ }^{28,29,36}$. Compulsory contraception is required for women of childbearing age who intend to use miltefosine ${ }^{37}$. Furthermore, as a precaution, conception should be delayed for $2^{36}$ to 4 months $^{38}$ after treatment ends. There is no rating for the use of miltefosine during pregnancy because it is not registered by the FDA (Table 3).

Nursing mothers: according to the WHO, meglumine antimoniate and pentamidine isethionate are the only two drugs for ATL treatment that are compatible with breastfeeding ${ }^{20}$ (Table 3). Data regarding the use of amphotericin B by breastfeeding women are lacking ${ }^{22}$.

The $\mathrm{SbV}$ concentration in breast milk is low $(3.5 \mathrm{mg} \mathrm{Sb} / \mathrm{ml})$, with little effect on the newborn ${ }^{39}$. The excretion of amphotericin $\mathrm{B}$, pentamidine isethionate and miltefosine in breast milk is 
TABLE 3 - Safety recommendations for drugs used for American tegumentary leishmaniasis treatment in pregnant women and nursing mothers.

\begin{tabular}{lcc}
\hline Drug & Pregnancy* & Breastfeeding $\dagger$ \\
\hline Meglumine antimoniate & C & CB \\
Amphotericin B & B & NA \\
Liposomal amphotericin & B & NA \\
Pentamidine & C & CB \\
Miltefosine & NAt & NA
\end{tabular}

*Index of drug toxicity criteria adopted by the FDA, United States of America ${ }^{18-20}$; $\uparrow$ Index of Breastfeeding and Maternal Medication Recommendations for Drugs by World Health Organization ${ }^{18-20}$; $\$$ Although miltefosine is not registered by the FDA, its use is contraindicated in pregnancy; B: remote possibility of fetal harm; animal studies showed no risk to the fetus; there are no studies in humans; $\mathrm{C}$ : possible harm to the fetus; insufficient controlled studies in humans and animals; CB: compatible with breastfeeding; FDA: Food and Drug Administration. NA: not available.

unknown. Therefore, these drugs are not recommended in nursing mothers. No data are available regarding the risk to the child ${ }^{18}$ (Table 3).

Children: $m$ Most studies found included children between 2 and 12 years of age. According to the Brazilian health authorities, meglumine antimoniate is the drug of choice to treat pediatric patients ${ }^{39}$. The maximum daily dose of $\mathrm{SbV}$ for children under 12 years of age must not exceed $121.5 \mathrm{mg}(7.5 \mathrm{ml})$, and treatment of children under 18 months is not recommended ${ }^{39}$. However, CL treatment with meglumine antimoniate is less effective in children than in adults ${ }^{40-42}$. The lower efficacy may result from the pathogenicity of the parasite or the particular immune response of this age group ${ }^{40,42}$. Meglumine antimoniate for the treatment of $\mathrm{CL}$ seems to reduce blood cell counts and liver enzymes more frequently in children than in adults and appears to significantly increase serum amylase and lipase levels ${ }^{43}$. A sickle cell crisis has been reported as an adverse effect of CL treatment with meglumine antimoniate in a 6-year-old child in Colombia ${ }^{44}$.

Intra-lesional meglumine antimoniate seems to be an alternative for children with CL. An infusion of the maximum dose of $10 \mathrm{ml}$ at intervals of 7 to 15 days proved to be more effective and better tolerated than conventional intramuscular treatment in this age group in $\mathrm{Brazil}^{45}$.

Scarce data are available for ATL treatment with amphotericin $B$ in children. We found three case reports of children infected by Leishmania (Viannia) braziliensis treated with amphotericin deoxycholate whose CL lesions were cured without adverse effects $^{46,47}$. In contrast, VL treatment with liposomal amphotericin showed no difference in efficacy or safety between children and adults $^{18}$. In a double-blind study with pediatric patients (16 years of age or younger), liposomal amphotericin presented a lower incidence of hypokalemia, chills, vomiting and hypertension than amphotericin deoxycholate ${ }^{18}$.
Pentamidine treatment for $\mathrm{CL}$ is considered to represent an unlabeled use by the FDA ${ }^{18}$. The $\mathrm{CDC}$ recommended dose for children is 2 to $3 \mathrm{mg} / \mathrm{kg}$ IM or IV on alternate days for 4-7 doses $^{19}$. In Brazil, a 14 year-old girl with CL was cured after pentamidine treatment ${ }^{48}$, and a recent randomized controlled trial (RCT) including children with CL showed similar efficacy of pentamidine and meglumine in the treatment of ATL $^{49}$ caused by Leishmania (Viannia) guyanensis.

Oral administration and low toxicity favor the use of miltefosine in this age group ${ }^{50}$. There were two RCTs including children 2 to 12 years of age with CL in Brazil ${ }^{16,17}$ and one in Colombia ${ }^{50}$. The cure rate of miltefosine was non-inferior compared to meglumine antimoniate ${ }^{16,17,50}$. However, miltefosine was less effective for children infected by Leishmania guyanensis in Brazil ${ }^{17}$, possibly because of lower plasma concentrations of miltefosine in children ${ }^{51}$. The most frequently reported adverse event was vomiting (12/28 children; $43 \%)^{17}$.

The elderly: in the treatment of ATL, the patient's age should be considered, as most adverse reactions occur in individuals over 50 years of age $\mathrm{e}^{52}$. Pentavalent antimonials are the most widely adopted drugs for CL treatment in elderly patients. However, there are no pharmacokinetics studies in this group. The incidence of CL in the population over 65 years of age is increasing significantly ${ }^{53}$. American tegumentary leishmaniasis patients between 60 and 92 years of age were studied in Brazil. Of the 44 patients, $36(82 \%)$ had CL, and eight (18\%) had mucocutaneous leishmaniasis (MCL). Low-dose meglumine antimoniate was administered three times a day $(5 \mathrm{mg} / \mathrm{kg} /$ day $)$ with complete resolution in $33(75 \%)$ cases. However, treatment was discontinued in nine $(21 \%)$ subjects because of moderate to severe adverse effects, such as hypoglycemia, anemia, pancreatitis, increased transaminase levels, thrombocytopenia and renal failure ${ }^{54}$. Adverse events such as renal tubular dysfunction and hematological, heart and liver abnormalities are common causes of treatment interruption in this age group. Advanced age is one of the risk factors for tinnitus, which affects $5 \%$ of elderly patients using meglumine antimoniate ${ }^{53}$. Electrocardiogram abnormalities associated with meglumine antimoniate are more frequent in the elderly. Angiotensinconverting enzyme inhibitors may have a cardioprotective effect in older patients using meglumine antimoniate ${ }^{55}$. Secondary infection was also observed more frequently in patients older than 45 years of age $(p<0.04)$ subjected to meglumine antimoniate intralesional treatment for $\mathrm{CL}^{56}$. This is an effective and less toxic alternative treatment for CL patients with contraindications to systemic therapy ${ }^{57}$. Cutaneous leishmaniasis patients younger than 65 years of age without co-morbidities can be safely and effectively treated in specialist centers with parenteral $\mathrm{SbV}$ without hospital admission ${ }^{58}$.

No studies were found for ATL treatment with amphotericin in the elderly. However, it was not necessary to change the standard dose of liposomal amphotericin in elderly patients treated for other diseases. Careful monitoring is recommended ${ }^{18}$.

There were also no studies for ATL treatment with pentamidine in elderly patients. A 64-year-old woman who developed severe hypokalemia under meglumine antimoniate treatment for Old World ML was successfully treated with miltefosine ${ }^{59}$. 
Patients with kidney disease: pentavalent antimonials are contraindicated for ATL treatment in patients with severe renal impairment. Renal evaluation studies are rare in ATL. Urinary concentration and acidification defects were found in a significant number of patients treated with $\mathrm{SbV}^{60}$. These drugs should therefore be used with caution in patients with any renal dysfunction. A patient with previous renal problems presenting with MCL was submitted to a course of prednisolone combined with the SbV treatment and had a good response to treatment. Adjuvant glucocorticoid therapy provided symptomatic relief ${ }^{61}$.

Liposomal amphotericin may represent a safe, efficient and less toxic alternative therapy for ATL; it was safely used in a patient with kidney failure and diabetes mellitus who was on dialysis. Healing of CL lesions was achieved with a total dose of $600 \mathrm{mg}^{62}$ even though amphotericin B is associated with dose-dependent nephrotoxicity, particularly when the daily dose is greater than $35 \mathrm{mg}$. Risk factors that predispose patients to this condition are as follows: body weight over $90 \mathrm{~kg}$, concomitant cyclosporine or aminoglycoside usage, chronic renal failure $(\mathrm{CRF})^{63}$, male sex, advanced age and jaundice ${ }^{64}$. Patients with more than two risk factors for nephrotoxicity are potential candidates for alternative therapy ${ }^{63}$. Amphotericin B delivered as a locally prepared lipid emulsion or in liposomes may reduce nephrotoxicity ${ }^{65}$.

A randomized controlled trial conducted in Peru with MCL patients ${ }^{66}$ showed that hydration with oral hyperosmolar solution was as effective as parenteral hydration to prevent glomerular injury caused by amphotericin B. Laboratory studies indicate that hypokalemia predisposes patients to tubular damage from amphotericin $\mathrm{B}^{67}$.

Pentamidine is contraindicated in patients with CRF. This drug has slow excretion from the body and can accumulate in the kidneys and liver. Thus, pentamidine must be used with caution in patients with renal dysfunction ${ }^{18}$.

Miltefosine may be an alternative for ATL treatment in patients with renal impairment. There is a case report of CL in an elderly patient with CRF who was treated with $1.8 \mathrm{mg} /$ $\mathrm{kg} /$ day of miltefosine for 28 days. The patient's skin lesions healed and no adverse events were reported ${ }^{68}$. However, $1 \%$ of miltefosine patients may develop nephrotoxicity ${ }^{69}$. Mild to moderate increases in creatinine are an adverse effect related to miltefosine ${ }^{9}$. Therefore, renal function should be monitored.

A recent literature review on renal involvement in VL suggests that $\mathrm{SbV}$, amphotericin $\mathrm{B}$, pentamidine, miltefosine, paromomycin and sitamaquine may be associated with a high risk of renal toxicity ${ }^{70}$.

Patients with heart disease: meglumine antimoniate is contraindicated in patients with heart disease ${ }^{39}$, and it is associated with arrhythmias and conduction disorders in adults with no previous heart disease ${ }^{71}$. Electrocardiographic QTc interval prolongations are an adverse effect related to $\mathrm{SbV}^{9,61}$. However, these changes are usually reversible after drug discontinuation. A case of pericarditis was reported in a CL patient treated with systemic meglumine antimoniate ${ }^{72}$.

Amphotericin B is also associated with the occurrence of arrhythmias. Therefore, its use for ATL treatment in cardiac patients requires close monitoring. Rapid infusions should be avoided to prevent arrhythmias and local irritation ${ }^{18}$.
Pentamidine should be used with caution in patients with preexisting heart disease. Hypotension, hypertension and arrhythmia, including ventricular tachycardia, have been reported. Pentamidine is known to prolong the QT interval and subsequently increases the risk of occurrence of torsade de pointes ${ }^{18}$.

We could not find a description in the medical literature of cardiac adverse events during ATL treatment with miltefosine ${ }^{13,14,16,17}$.

Patients with liver disease: there are no studies of ATL treatment with meglumine antimoniate in patients with liver impairment. Meglumine antimoniate is contraindicated in patients with severe liver disease. Mild to moderate increases in liver and pancreatic enzyme levels are adverse effects related to $\mathrm{SbV}^{9}$. Case reports of hepatitis arising from its use have been described. Therefore, another drug is recommended for treatment ${ }^{18}$.

The pharmacokinetics of liposomal amphotericin were not studied in patients with chronic liver disease ${ }^{73}$.

Pentamidine should be used with caution in patients with liver dysfunction ${ }^{18}$.

The clearance of miltefosine is performed by hepatocyte phospholipases $^{74}$, and $1 \%$ of patients using it may develop hepatotoxicity ${ }^{69}$. Mild to moderate increases in aminotransferase levels were adverse effects related to miltefosine ${ }^{9}$. Therefore, laboratory monitoring of liver function is recommended.

Patients with suppressed immune systems: ATL infection is emerging as a result of immunosuppression, and HIV is the most common cause ${ }^{62,75-88}$. Bone marrow or solid organ transplantation ${ }^{89-95}$ and therapy with immunosuppressive or biologic drugs $^{96-98}$ also have been associated with the appearance of ATL. In immunosuppressed patients, CL is characterized by atypical cutaneous lesions and persistent negativity of diagnostic tests ${ }^{91}$.

Human immunodeficiency virus/acquired immunodeficiency syndrome: the association between ATL and HIV-AIDS has increasingly been described in many regions of the world ${ }^{99}$ together with immune reconstitution inflammatory syndrome presentation $^{82,84,85,100}$.

The evidence for the treatment of co-infection with HIV and LC is still very limited ${ }^{101}$. Generally, systemic therapy is used to prevent the spread of the parasite. The same approach used for immunocompetent individuals is applied with weekly monitoring ${ }^{39}$. Recurrences are frequent ${ }^{80,86}$ and fatal cases have been reported ${ }^{86}$. A series of 15 patients with ATL/HIV-AIDS association in Brazil was recently published, where only seven patients were successfully treated at the first attempt ${ }^{99}$. Leishmaniasis was the first opportunistic infection in $60 \%$ of patients in another case series of $23 \mathrm{HIV}$ patients recently investigated in Brazil. The cluster of differentiation antigen 4 (CD4)+ T-cell count was below 200 cells $/ \mathrm{mm}$ in $80 \%$ of cases and did not increase after clinical remission despite antiretroviral therapy. The first drug chosen to treat the cases was $\mathrm{SbV}$, but the therapeutic regimen was altered to amphotericin B in 12 of 17 cases because of side effects. Relapses were reported in $56 \%$ of the patients ${ }^{102}$. 
An HIV-positive patient with MCL caused by L. braziliensis was treated successfully with a short course of meglumine antimoniate $^{75}$. However, SbV showed no therapeutic response in four LM co-infected patients. Cardiotoxicity occurred in three cases. Pentamidine and amphotericin were more effective ${ }^{78}$. Pentamidine was used to treat HIV-infected patients with CL caused by L. guyanensis in a case-control study in French Guiana. HIV patients had a higher rate of recurrence or reinfection and a lower rate of recovery after pentamidine treatment ${ }^{80}$.

In Bolivia, amphotericin deoxycholate was used for 80 days to treat HIV-infected patients with CL caused by L. braziliensis without success ${ }^{87}$. However, liposomal amphotericin showed a good response in two cases of co-infected MCL and HIV patients who had not responded to meglumine antimoniate ${ }^{76,103}$. In addition, liposomal amphotericin was also used successfully in co-infected CL and HIV patients with a $1,500 \mathrm{mg} \operatorname{dose}^{62}$.

Patients co-infected with HIV and ATL have been treated with miltefosine with initial success, but then relapsed ${ }^{104,105}$. However, Old World CL patients with HIV were cured with miltefosine after treatment failure with conventional amphotericin B, liposomal amphotericin and sodium stibogluconate ${ }^{81,83}$. An experimental study in immunosuppressed rats suggests that miltefosine may be useful in both the acute and maintenance phases ${ }^{77}$.

Other types of immune system suppression - There were no studies of ATL treatment in patients with other types of immune system suppression. However, treatment of patients with VL and Old World CL has been reported. In transplant recipients,
$\mathrm{CL}$ and ML are rare and usually there is a time interval between transplantation and disease manifestation ${ }^{106}$. Reviews of organ transplant recipients with leishmaniasis show that the majority of patients have undergone renal transplantation, and most cases are identified as visceral-type disease $\mathrm{e}^{93,107-109}$.

Patients presenting LV after organ transplantation treated with $\mathrm{SbV}$ presented with amylase and lipase elevation in addition to pancreatitis ${ }^{110}$. In contrast, a CL case treated with intralesional injections of meglumine antimonate was reported after 20 months of infliximab treatment for ankylosing spondylitis (uveitis and arthritis). Infliximab was discontinued, and local treatment led to rapid improvement ${ }^{111}$.

An 83-year-old patient with myelodysplastic syndrome was treated successfully with liposomal amphotericin for CL caused by Leishmania major without adverse effects ${ }^{112}$. Renal transplantation patients presenting with VL also had a good response to liposomal amphotericin ${ }^{110,113}$. However, toxicity occurred in patients with LV after heart transplantation, and treatment needed to be interrupted ${ }^{114}$.

Use of pentamidine or miltefosine has not been reported in other populations of immunosuppressed patients ${ }^{115}$.

In conclusion, a summary of the more apropriate ATL therapeutic options for each special population reviewed in this paper is shown in Table 4. A common finding in all groups is the low or very low quality of evidence. There is a need for controlled studies of higher quality, ideally randomized controlled trials. Post-marketing surveillance programs could play a role in filling the existing gaps in knowledge.

TABLE 4 - Summary of the proper American tegumentary leishmaniasis treatment options reviewed for each special population.

\begin{tabular}{|c|c|c|}
\hline Special populations & Drug of choice & Evidence level \\
\hline Nursing mother & $\mathrm{NA} \dagger$ & NA \\
\hline Children & $\begin{array}{l}\text { meglumine antimoniate or miltefosine for Leishmania braziliensis; } \\
\text { meglumine antimoniate or pentamidine for Leishmania guyanensis }\end{array}$ & low \\
\hline The elderly & $\begin{array}{c}\text { meglumine antimoniate } \\
\text { (low dose or intralesional injections)* }\end{array}$ & very low \\
\hline Renal disease & amphotericin B or miltefosine & very low \\
\hline Heart disease & amphotericin B or pentamidine or miltefosine (used with caution) ${ }^{18-20}$ & very low \\
\hline Liver disease & NA & NA \\
\hline
\end{tabular}

NA: not available. $\dagger$ : according to the World Health Organization, the drugs for American tegumentary leishmaniasis treatment that are compatible with breastfeeding are meglumine antimoniate and pentamidine isethionate ${ }^{20}$. This evidence however, was not found in clinical trials and observational studies, the study design that was eligible for inclusion in this review. *To avoid toxicity or when systemic therapy is contraindicated.

\section{CONFLICT OF INTEREST}

The authors declare that there is no conflict of interest.

\section{REFERENCES}

1. González U, Pinart M, Reveiz L, Rengifo-Pardo M, Tweed J, Macaya A, et al. Designing and reporting clinical trials on treatments for cutaneous leishmaniasis. Clin Infect Dis 2010; 51:409-419. 
2. Sundar S, Chakravarty J. Leishmaniasis: an update of current pharmacotherapy. Expert Opin Pharmacother 2013; 14:53-63.

3. Olliaro P, Vaillant M, Arana B, Grogl M, Modabber F, Magill A, et al. Methodology of clinical trials aimed at assessing interventions for cutaneous leishmaniasis. PLoS Negl Trop Dis 2013; 7:e2130.

4. Reveiz L, Maia-Elkhoury AN, Nicholls RS, Romero GA, Yadon ZE. Interventions for American cutaneous and mucocutaneous leishmaniasis: a systematic review update. PLoS One 2013; 8:e61843.

5. Paniz Mondolfi AE, Duffey GB, Horton LE, Tirado M, Reyes Jaimes O, Perez-Alvarez A, et al. Intermediate/borderline disseminated cutaneous leishmaniasis. Int J Dermatol 2013; 52:446-455.

6. Reithinger R, Dujardin JC, Louzir H, Pirmez C, Alexander B, Brooker S. Cutaneous leishmaniasis. Lancet Infect Dis 2007; 7:581-596.

7. Tuon FF, Amato VS, Graf ME, Siqueira AM, Nicodemo AC, Amato Neto V. Treatment of New World cutaneous leishmaniasis-a systematic review with a meta-analysis. Int J Dermatol 2008; 47:109-124.

8. Mitropoulos P, Konidas P, Durkin-Konidas M. New World cutaneous leishmaniasis: updated review of current and future diagnosis and treatment. J Am Acad Dermatol 2010; 63:309-322.

9. Oliveira LF, Schubach AO, Martins MM, Passos SL, Oliveira RV, Marzochi MC, et al. Systematic review of the adverse effects of cutaneous leishmaniasis treatment in the New World. Acta Trop 2011; 118:87-96.

10. González U, Pinart M, Rengifo-Pardo M, Macaya A, Alvar J, Tweed JA. Interventions for American cutaneous and mucocutaneous leishmaniasis. Cochrane Database Syst Rev 2009; CD004834.

11. Soto J, Toledo J, Gutierrez P, Nicholls RS, Padilla J, Engel J, et al. Treatment of American cutaneous leishmaniasis with miltefosine, an oral agent. Clin Infect Dis 2001; 33:E57-E61.

12. Soto J, Arana BA, Toledo J, Rizzo N, Vega JC, Diaz A, et al. Miltefosine for new world cutaneous leishmaniasis. Clin Infect Dis 2004; 38:12661272 .

13. Soto J, Toledo J, Valda L, Balderrama M, Rea I, Parra R, et al. Treatment of Bolivian mucosal leishmaniasis with miltefosine. Clin Infect Dis 2007; 44:350-356.

14. Soto J, Rea J, Balderrama M, Toledo J, Soto P, Valda L, et al. Efficacy of miltefosine for Bolivian cutaneous leishmaniasis. Am J Trop Med Hyg 2008; 78:210-211.

15. Vélez I, López L, Sánchez X, Mestra L, Rojas C, Rodríguez E. Efficacy of miltefosine for the treatment of American cutaneous leishmaniasis. Am J Trop Med Hyg 2010; 83:351-356.

16. Machado PR, Ampuero J, Guimarães LH, Villasboas L, Rocha AT, Schriefer A, et al. Miltefosine in the treatment of cutaneous leishmaniasis caused by Leishmania braziliensis in Brazil: a randomized and controlled trial. PLoS Negl Trop Dis 2010; 4:e912.

17. Chrusciak-Talhari A, Dietze R, Chrusciak Talhari C, Silva RM, Gadelha Yamashita EP, Oliveira Penna G, et al. Randomized controlled clinical trial to access efficacy and safety of Miltefosine in the treatment of cutaneous leishmaniasis caused by Leishmania (Viannia) guyanensis in Manaus, Brazil. Am J Trop Med Hyg 2011; 84:255-260.

18. Food and Drug Administration (FDA) Website. U.S. Department of Health \& Human Services. FDA; 2011 [cited 2011 Jun 13]. Available at: http://www.fda.gov/default.html.

19. Centers for Disease Control and Prevention (CDC). Leishmania [Internet]. [cited 2011 Jun 10]. Available at: http://www.dpd.cdc.gov/dpdx/HTML/ PDF_Files/MedLetter/Leishmania.pdf.

20. World Health Organization (WHO). Recommendations for drugs in the Eleventh WHO Model List of Essential Drugs 2008 [Internet] [cited 2011 Jun 21]. Available at: http://whqlibdoc.who.int/hq/2002/55732.pdf.

21. Guyatt GH, Oxman AD, Vist GE, Kunz R, Falck-Ytter Y, Alonso-Coello $P$, et al. GRADE: an emerging consensus on rating quality of evidence and strength of recommendations. BMJ 2008; 336:924-926.

22. Njoku J, Gumeel D, Hermsen E. Antifungal Therapy in Pregnancy and Breastfeeding. Current Fungal Infection Reports. 2010; 4:62-69.
23. Dean JL, Wolf JE, Ranzini AC, Laughlin MA. Use of amphotericin B during pregnancy: case report and review. Clin Infect Dis 1994; 18:364-368.

24. Figueiró-Filho EA, El Beitune P, Queiroz GT, Somensi RS, Morais NO, Dorval ME, et al. Visceral leishmaniasis and pregnancy: analysis of cases reported in a central-western region of Brazil. Arch Gynecol Obstet 2008; 278:13-16.

25. Pagliano P, Carannante N, Rossi M, Gramiccia M, Gradoni L, Faella FS, et al. Visceral leishmaniasis in pregnancy: a case series and a systematic review of the literature. J Antimicrob Chemother 2005; 55:229-233.

26. Mueller M, Balasegaram M, Koummuki Y, Ritmeijer K, Santana MR, Davidson R. A comparison of liposomal amphotericin B with sodium stibogluconate for the treatment of visceral leishmaniasis in pregnancy in Sudan. J Antimicrob Chemother 2006; 58:811-815.

27. Léonard A, Gerber GB. Mutagenicity, carcinogenicity and teratogenicity of antimony compounds. Mutat Res 1996; 366:1-8.

28. Paumgartten FJ, Chahoud I. Embryotoxicity of meglumine antimoniate in the rat. Reprod Toxicol 2001; 15:327-331.

29. Miranda ES, Miekeley N, De-Carvalho RR, Paumgartten FJ. Developmental toxicity of meglumine antimoniate and transplacental transfer of antimony in the rat. Reprod Toxicol 2006; 21:292-300.

30. Morgan DJ, Guimaraes LH, Machado PR, D'Oliveira A, Almeida RP, Lago EL, et al. Cutaneous leishmaniasis during pregnancy: exuberant lesions and potential fetal complications. Clin Infect Dis 2007; 45:478-482.

31. Silveira BP, Araújo Sobrinho J, Leite LF, Sales MN, Gouveia MS, Mathias RL, et al. Premature birth after the use of pentavalent antimonial: case report. Rev Soc Bras Med Trop 2003; 36:523-525.

32. Adam GK, Abdulla MA, Ahmed AA, Adam I. Maternal and perinatal outcomes of visceral leishmaniasis (kala-azar) treated with sodium stibogluconate in eastern Sudan. Int J Gynaecol Obstet 2009; 107:208-210.

33. Ameen M. Cutaneous and mucocutaneous leishmaniasis: emerging therapies and progress in disease management. Expert Opin Pharmacother 2010; 11:557-569.

34. Minodier P, Jurquet AL, Noël G, Uters M, Laporte R, Garnier JM. Leishmaniasis treatment. Arch Pediatr 2010; 17:838-839.

35. Shukla AK, Singh BK, Patra S, Dubey VK. Rational approaches for drug designing against leishmaniasis. Appl Biochem Biotechnol 2010; 160:2208-2218.

36. Sindermann H, Engel J. Development of miltefosine as an oral treatment for leishmaniasis. Trans R Soc Trop Med Hyg 2006; 100 (suppl I):17-20.

37. Dorlo TP, van Thiel PP, Huitema AD, Keizer RJ, Vries HJ, Beijnen JH, et al. Pharmacokinetics of miltefosine in Old World cutaneous leishmaniasis patients. Antimicrob Agents Chemother 2008; 52:2855-2860.

38. Dorlo TP, Balasegaram M, Lima MA, Vries PJ, Beijnen JH, Huitema AD. Translational pharmacokinetic modelling and simulation for the assessment of duration of contraceptive use after treatment with miltefosine. J Antimicrob Chemother 2012; 67:1996-2004.

39. Ministério da Saúde. Secretaria de Vigilância Sanitária. Manual de Vigilância da Leishmaniose Tegumentar Americana. $2^{\text {nd }}$ ed. atual. Brasília: Editora do Ministério da Saúde; 2007.

40. Cruz A, Rainey PM, Herwaldt BL, Stagni G, Palacios R, Trujillo R, et al. Pharmacokinetics of antimony in children treated for leishmaniasis with meglumine antimoniate. J Infect Dis 2007; 195:602-608.

41. Layegh P, Rahsepar S, Rahsepar AA. Systemic meglumine antimoniate in acute cutaneous leishmaniasis: children versus adults. Am J Trop Med Hyg 2011; 84:539-542.

42. Palacios R, Osorio LE, Grajalew LF, Ochoa MT. Treatment failure in children in a randomized clinical trial with 10 and 20 days of meglumine antimonate for cutaneous leishmaniasis due to Leishmania viannia species. Am J Trop Med Hyg 2001; 64:187-193.

43. Layegh P, Khademi Z, Kiafar B. Side effects of systemic meglumine antimoniate in children with cutaneo us leishmaniasis: A prospective clinico-laborator y assess. Euro J Pediatric Dermatol 2012; 22:15. 
44. Garcerant D, Rubiano L, Blanco V, Martinez J, Baker NC, Craft N. Possible links between sickle cell crisis and pentavalent antimony. Am J Trop Med Hyg 2012; 86:1057-1061.

45. Gadelha AR, Oliveira WC, Assunção IJ, Dourado HV. Tratamento da leishmaniose tegumentar americana com injeções intralesionais de n-metil-glucamina. An Bras Dermatol 1990; 65:201.

46. Campos-Muñoz L, Quesada-Cortés A, Martín-Díaz MA, Rubio-Flores C, Lucas-Laguna R. Leishmania braziliensis: report of a pediatric imported case with response to liposomal amphotericin B. Actas Dermosifiliogr 2007; 98:42-44.

47. Rosal T, Artigao FB, Miguel MJ, Lucas R, Castillo F. Successful treatment of childhood cutaneous leishmaniasis with liposomal amphotericin B: report of two cases. J Trop Pediatr 2010; 56:122-124.

48. Sampaio RN, Paula CD. American cutaneous leishmaniasis in the Federal District. Rev Soc Bras Med Trop 1999; 32:523-528.

49. Neves LO, Talhari AC, Gadelha EP, Silva Júnior RM, Guerra JA, Ferreira LC, et al. A randomized clinical trial comparing meglumine antimoniate, pentamidine and amphotericin B for the treatment of cutaneous leishmaniasis by Leishmania guyanensis. An Bras Dermatol 2011; 86:1092-1101.

50. Rubiano LC, Miranda MC, Muvdi Arenas S, Montero LM, RodríguezBarraquer I, Garcerant D, et al. Noninferiority of miltefosine versus meglumine antimoniate for cutaneous leishmaniasis in children. J Infect Dis 2012; 205:684-692.

51. Berman J. Current treatment approaches to leishmaniasis. Curr Opin Infect Dis 2003;16:397-401.

52. Diniz DS, Costa AS, Escalda PM. The effect of age on the frequency of adverse reactions caused by antimony in the treatment of American tegumentary leishmaniasis in Governador Valadares, State of Minas Gerais, Brazil. Rev Soc Bras Med Trop 2012; 45:597-600.

53. Araujo-Melo MH, Meneses AM, Schubach AO, Moreira JS, ConceiçãoSilva F, Salgueiro MM, et al. Risk factors associated with dizziness during treatment of mucosal leishmaniasis with meglumine antimoniate: 16-year retrospective study of cases from Rio de Janeiro, Brazil. J Laryngol Otol 2010; $124: 1056-1060$.

54. Vasconcellos ECF, Schubach AO, Valete-Rosalino CM, Coutinho RS, Conceição-Silva F, Salgueiro MM, et al. American tegumentary leishmaniasis in older adults: 44 cases treated with an intermittent low-dose antimonial schedule in Rio de Janeiro, Brazil. J Am Geriatr Soc 2010; 58:614-616.

55. Rodrigues AM, Hueb M, Nery AF, Fontes CJ. Possible cardioprotective effect of angiotensin-converting enzyme inhibitors during treatment of American tegumentary leishmaniasis with meglumine antimoniate. Acta Trop 2007; 102:113-118.

56. Esfandiarpour I, Farajzadeh S, Rahnama Z, Fathabadi EA, Heshmatkhah A. Adverse effects of intralesional meglumine antimoniate and its influence on clinical laboratory parameters in the treatment of cutaneous leishmaniasis. Int J Dermatol 2012; 51:1221-1225.

57. Vasconcellos EC, Pimentel MI, Schubach AO, Oliveira RV, AzeredoCoutinho RB, Silva FC, et al. Intralesional meglumine antimoniate for treatment of cutaneous leishmaniasis patients with contraindication to systemic therapy from Rio de Janeiro (2000 to 2006). Am J Trop Med Hyg 2012; 87:257-260.

58. Wise ES, Armstrong MS, Watson J, Lockwood DN. Monitoring toxicity associated with parenteral sodium stibogluconate in the day-case management of returned travellers with New World cutaneous leishmaniasis [corrected]. PLoS Negl Trop Dis 2012; 6:e1688.

59. Neumayr AL, Walter C, Stoeckle M, Braendle N, Glatz K, Blum JA. Successful treatment of imported mucosal Leishmania infantum leishmaniasis with miltefosine after severe hypokalemia under meglumine antimoniate treatment. J Travel Med 2012; 19:124-126.

60. Oliveira RA, Lima CG, Mota RM, Martins AM, Sanches TR, Seguro AC, et al. Renal function evaluation in patients with American cutaneous leishmaniasis after specific treatment with pentavalent antimonial. BMC Nephrol 2012; 13:44.
61. Brostoff JM, Lockwood DN. Glucocorticoids as a novel approach to the treatment of disabling side effects of sodium stibogluconate. J Clin Pharm Ther 2012; 37:122-123.

62. Amato VS, Rabello A, Rotondo-Silva A, Kono A, Maldonado TP, Alves IC, et al. Successful treatment of cutaneous leishmaniasis with lipid formulations of amphotericin B in two immunocompromised patients. Acta Trop 2004; 92:127-132.

63. Harbarth S, Pestotnik SL, Lloyd JF, Burke JP, Samore MH. The epidemiology of nephrotoxicity associated with conventional amphotericin B therapy. Am J Med 2001; 111:528-534.

64. Oliveira MJ, Silva Júnior GB, Abreu KL, Rocha NA, Garcia AV, Franco LF, et al. Risk factors for acute kidney injury in visceral leishmaniasis (KalaAzar). Am J Trop Med Hyg 2010; 82:449-453.

65. Mistro S, Maciel IM, Menezes RG, Maia ZP, Schooley RT, Badaró R. Does lipid emulsion reduce amphotericin B nephrotoxicity? A systematic review and meta-analysis. Clin Infect Dis 2012; 54:1774-1777.

66. Echevarria J, Seas C, Cruz M, Chávez E, Campos M, Cieza J, et al. Oral rehydration solution to prevent nephrotoxicity of amphotericin B. Am J Trop Med Hyg 2006; 75:1108-1112.

67. Bernardo JF, Murakami S, Branch RA, Sabra R. Potassium depletion potentiates amphotericin-B-induced toxicity to renal tubules. Nephron 1995; 70:235-241.

68. Zea DF, Prager M, Figueroa RA, Miranda MC. Mucosal complication of cutaneous leishmaniasis. Biomédica 2009; 29:9-11.

69. National Vector Borne Disease Control Programme (NVBDCP) [Internet]. Guidelines on use of miltefosine [Cited 2011 Jun 10]. Available at: http:// nvbdcp.gov.in/Doc/Guidelines\%20on\%20miltefosine.pdf.

70. Clementi A, Battaglia G, Floris M, Castellino P, Ronco C, Cruz DN. Renal involvement in leishmaniasis: A review of the literature. NDT Plus $2011 ; 4: 147-152$

71. Sadeghian G, Ziaei H, Sadeghi M. Electrocardiographic changes in patients with cutaneous leishmaniasis treated with systemic glucantime. Ann Acad Med Singapore 2008; 37:916-918.

72. Eryilmaz A, Durdu M, Baba M, Bal N, Yiğit F. A case with two unusual findings: cutaneous leishmaniasis presenting as panniculitis and pericarditis after antimony therapy. Int J Dermatol 2010; 49:295-297.

73. Kan VL, Bennett JE, Amantea MA, Smolskis MC, McManus E, Grasela $\mathrm{DM}$, et al. Comparative safety, tolerance, and pharmacokinetics of amphotericin B lipid complex and amphotericin B desoxycholate in healthy male volunteers. J Infect Dis 1991; 164:418-421.

74. UngerC,FleerE, DamenzW, HilgardP,Nagel G, EiblH.Hexadecylphosphocholine: determination of serum concentrations in rats. J Lipid Mediat 1991; 3:71-78.

75. Machado ES, Braga MP, Cruz AM, Coutinho SG, Vieira AR, Rutowitsch MS, et al. Disseminated American muco-cutaneous leishmaniasis caused by Leishmania braziliensis braziliensis in a patient with AIDS: a case report. Mem Inst Oswaldo Cruz 1992; 87:487-492.

76. Amato VS, Nicodemo AC, Amato JG, Boulos M, Amato-Neto V. Mucocutaneous leishmaniasis associated with HIV infection treated successfully with liposomal amphotericin B (AmBisome). J Antimicrob Chemother 2000; 46:341-342.

77. Murray HW. Suppression of posttreatment recurrence of experimental visceral Leishmaniasis in T-cell-deficient mice by oral miltefosine. Antimicrob Agents Chemother 2000; 44:3235-3236.

78. Sampaio RN, Salaro CP, Resende P, de Paula CD. American cutaneous leishmaniasis associated with HIV/AIDS: report of four clinical cases. Rev Soc Bras Med Trop 2002; 35:651-654

79. Puig L, Pradinaud R. Leishmania and HIV co-infection: dermatological manifestations. Ann Trop Med Parasitol 2003; 97 (suppl I):107-114.

80. Couppié P, Clyti E, Sobesky M, Bissuel F, Del Giudice P, Sainte-Marie $\mathrm{D}$, et al. Comparative study of cutaneous leishmaniasis in human immunodeficiency virus (HIV)-infected patients and non-HIV-infected patients in French Guiana. Br J Dermatol 2004; 151:1165-1171. 
81. Sindermann H, Engel KR, Fischer C, Bommer W, Program MCU. Oral miltefosine for leishmaniasis in immunocompromised patients: compassionate use in 39 patients with HIV infection. Clin Infect Dis 2004; 39:1520-1523.

82. Posada-Vergara MP, Lindoso JA, Tolezano JE, Pereira-Chioccola VL, Silva MV, Goto H. Tegumentary leishmaniasis as a manifestation of immune reconstitution inflammatory syndrome in 2 patients with AIDS. J Infect Dis 2005; 192:1819-1822.

83. Schraner C, Hasse B, Hasse U, Baumann D, Faeh A, Burg G, et al. Successful treatment with miltefosine of disseminated cutaneous leishmaniasis in a severely immunocompromised patient infected with HIV-1. Clin Infect Dis 2005; 40:e120-124.

84. Sinha S, Fernández G, Kapila R, Lambert WC, Schwartz RA. Diffuse cutaneous leishmaniasis associated with the immune reconstitution inflammatory syndrome. Int J Dermatol 2008; 47:1263-1270.

85. Chrusciak-Talhari A, Ribeiro-Rodrigues R, Talhari C, Silva RM, Ferreira LC, Botileiro SF, et al. Tegumentary leishmaniasis as the cause of immune reconstitution inflammatory syndrome in a patient co-infected with human immunodeficiency virus and Leishmania guyanensis. Am J Trop Med Hyg 2009; 81:559-564.

86. Lindoso JA, Barbosa RN, Posada-Vergara MP, Duarte MI, Oyafuso LK, Amato VS, et al. Unusual manifestations of tegumentary leishmaniasis in AIDS patients from the New World. Br J Dermatol 2009; 160:311-318.

87. Torrico F, Parrado R, Castro R, Marquez CJ, Torrico MC, Solano M, et al. Co-Infection of Leishmania (Viannia) braziliensis and HIV: report of a case of mucosal leishmaniasis in Cochabamba, Bolivia. Am J Trop Med Hyg 2009; 81:555-558.

88. Soni P, Prasad N, Khandelwal K, Ghiya BC, Mehta RD, Bumb RA, et al. Unresponsive cutaneous leishmaniasis and HIV co-infection: report of three cases. Indian J Dermatol Venereol Leprol 2011; 77:251.

89. Gontijo CM, Pacheco RS, Orefice F, Lasmar E, Silva ES, Melo MN. Concurrent cutaneous, visceral and ocular leishmaniasis caused by Leishmania (Viannia) braziliensis in a kidney transplant patient. Mem Inst Oswaldo Cruz 2002; 97:751-753.

90. Mirzabeigi M, Farooq U, Baraniak S, Dowdy L, Ciancio G, Vincek V. Reactivation of dormant cutaneous Leishmania infection in a kidney transplant patient. J Cutan Pathol 2006; 33:701-704.

91. Ozcan D, Seçkin D, Allahverdiyev AM, Weina PJ, Aydin H, Ozçay F, et al. Liver transplant recipient with concomitant cutaneous and visceral leishmaniasis. Pediatr Transplant 2007; 11:228-232.

92. Antinori S, Schifanella L, Corbellino M. Leishmaniasis: new insights from an old and neglected disease. Eur J Clin Microbiol Infect Dis 2012; 31:109-118.

93. Zandieh A, Zandieh B, Dastgheib L. Dissemination of localized cutaneous leishmaniasis in an organ transplant recipient: case report and literature review. Int J Dermatol 2013; 52:59-62.

94. Muñoz P, Valerio M, Puga D, Bouza E. Parasitic infections in solid organ transplant recipients. Infect Dis Clin North Am 2010; 24:461-495.

95. Ponticelli C, Bencini PL. Nonneoplastic mucocutaneous lesions in organ transplant recipients. Transpl Int 2011; 24:1041-1050.

96. Saha M, Shipley D, McBride S, Kennedy C, Vega-Lopez F. Atypical cutaneous leishmaniasis in two patients receiving low-dose methotrexate. Br J Dermatol 2006; 155:830-833.

97. Tuon FF, Sabbaga Amato V, Floeter-Winter LM, Andrade Zampieri R, Amato Neto V, Siqueira França FO, et al. Cutaneous leishmaniasis reactivation 2 years after treatment caused by systemic corticosteroids first report. Int J Dermatol 2007; 46:628-630.
98. Pitini V, Cascio A, Arrigo C, Altavilla G. Visceral leishmaniasis after alemtuzumab in a patient with chronic lymphocytic leukaemia. $\mathrm{Br} \mathrm{J}$ Haematol 2012; 156:1.

99. Guerra JA, Coelho LI, Pereira FR, Siqueira AM, Ribeiro RL, Almeida TM, et al. American tegumentary leishmaniasis and HIV-AIDS association in a tertiary care center in the Brazilian Amazon. Am J Trop Med Hyg 2011; 85:524-527.

100.Amerson EH, Maurer TA. Immune reconstitution inflammatory syndrome and tropical dermatoses. Dermatol Clin 2011; 29:39-43.

101.Alvar J, Aparicio P, Aseffa A, Den Boer M, Cañavate C, Dedet JP, et al. The relationship between leishmaniasis and AIDS: the second 10 years. Clin Microbiol Rev 2008; 21:334-359.

102.Alexandrino-de-Oliveira P, Santos-Oliveira JR, Dorval ME, Da-Costa F, Pereira GR, Cunha RV, et al. HIV/AIDS-associated visceral leishmaniasis in patients from an endemic area in Central-west Brazil. Mem Inst Oswaldo Cruz 2010; 105:692-697.

103.Amato VS, Tuon FF, Camargo RA, Souza RM, Santos CR, Nicodemo AC. Can we use a lower dose of liposomal amphotericin B for the treatment of mucosal American leishmaniasis? Am J Trop Med Hyg 2011; 85: 818-819.

104. Soto J, Soto P. Oral miltefosine to treat leishmaniasis. Biomedica 2006; 26 (supl I):207-217.

105.Pérez C, Solías Y, Rodríguez G. Diffuse cutaneous leishmaniasis in a patient with AIDS. Biomedica 2006; 26:485-497.

106.Kotton CN, Lattes R, Practice AIDCo. Parasitic infections in solid organ transplant recipients. Am J Transplant. 2009; 9 (suppl IV):234-251.

107.Simon I, Wissing KM, Del Marmol V, Antinori S, Remmelink M, Nilufer Broeders E, et al. Recurrent leishmaniasis in kidney transplant recipients: report of 2 cases and systematic review of the literature. Transpl Infect Dis 2011; 13:397-406.

108.Bacha MM, Abderrahim E, Ounissi M, Chaouech D, Cherif M, Turki S, et al. Association of post-transplant lymphoproliferative disease and visceral leishmaniasis after kidney transplantation. Nephrol Ther 2011; 7:488-493.

109.Postorino MC, Bellantoni M, Catalano C, Caridi G, Rosa M, Seck S, et al. Visceral leishmaniasis reactivation in transplant patients: a minireview with report of a new case. J Nephrol 2011; 24:530-534.

110. Boletis JN, Pefanis A, Stathakis C, Helioti H, Kostakis A, Giamarellou H. Visceral leishmaniasis in renal transplant recipients: successful treatment with liposomal amphotericin B (AmBisome). Clin Infect Dis 1999; 28:1308-1309.

111. Bousquet E, Mura F, Villain M, Rivière S, Konate A, Schneider C. Infectious complications in patients treated with anti-TNF-alpha: two cases of leishmaniasis. J Fr Ophtalmol 2012; 35:695-699.

112. Prokopakis EP, Panagiotaki IE, Papadakis IA, Vardouniotis AS, Lagoudianakis GM, Velegrakis GA. Immunocompromised patient with an ulcerated nasolabial skin lesion. BMJ 2010; 340:c1444.

113. Veroux M, Corona D, Giuffrida G, Cacopardo B, Sinagra N, Tallarita T, et al. Visceral leishmaniasis in the early post-transplant period after kidney transplantation: clinical features and therapeutic management. Transpl Infect Dis 2010; 12:387-391.

114. Frapier JM, Abraham B, Dereure J, Albat B. Fatal visceral leishmaniasis in a heart transplant recipient. J Heart Lung Transplant 2001; 20:912-913.

115. Sindermann H, Croft SL, Engel KR, Bommer W, Eibl HJ, Unger C, et al. Miltefosine (Impavido): the first oral treatment against leishmaniasis. Med Microbiol Immunol 2004; 193:173-180. 